\title{
FROM ADOLESCENT NEUROGENESIS TO SCHIZOPHRENIA: OPPORTUNITIES, CHALLENGES AND PROMISING INTERVENTIONS
}

\author{
Adele Quartini', Francesca Pacitti ${ }^{2}$, Giuseppe Bersani ${ }^{1}$, and Angela Iannitelli ${ }^{2,3^{*}}$ \\ ${ }^{1}$ Department of Medical-Surgical Sciences and Biotechnologies, Faculty of Pharmacy and Medicine, \\ Sapienza University, DSM ASL/LT - Unit of Psychiatry, A. Fiorini Hospital, Terracina (LT), Rome, Italy, \\ ${ }^{2}$ Department of Biotechnological and Applied Clinical Sciences, University of L'Aquila, Rome, Italy, \\ ${ }^{3}$ Italian Psychoanalytical Society (SPI), Rome, Italy, and International Psychoanalytical Association \\ (IPA), London, UK
}

\section{ABSTRACT}

Schizophrenia is a maldevelopmental disease with multifactorial etiopathogenesis linked to disturbances in the prenatal/ perinatal environment and to social factors and/or addictive drugs consumption during adolescencelyoung adulthood. Adolescence has been demonstrated to represent a very sensitive period for brain development. Exposure to adverse life events (chronic social isolation and/or instability) and/or addictive drugs (opioids, cocaine, cannabinoids, alcohol, nicotine) during adolescence has been linked to deviations in the normal neurodevelopment, producing a brain particularly at risk of mental diseases. Several psychopharmacological drugs and environmental factors have been reported to protect against the detrimental effect on neurogenesis caused by the aforementioned genetic and/or epigenetic vulnerabilities. Nerve growth factor (NGF) is one of the strongest stimuli of adult/adolescent neurogenesis and a promising neuromodulator to prevent and/or ameliorate the various behavioral and cognitive schizophrenic symptoms. Biomed Rev 2017; 28: 62-69.

Key words: schizophrenia, neurodevelopment, adolescence, stem cells, adult neurogenesis, addictive drugs, life events, NGF

\section{INTRODUCTION}

Schizophrenia (SCZ) is considered a disease of abnormal brain development, with an elevated incidence of the disease being linked to a wide range of disturbances in the prenatal/ perinatal environment and to social factors and/or addictive drugs consumption during adolescence/young adulthood (1). An appropriate proliferation, migration, differentiation, synaptogenesis, and finally pruning of new neurons represent essential steps for a healthy brain development (2). For over a century, it has been thought that the capacity of germinal layers to generate neurons was restricted to the embryonic period, and that new neurons could not be added to the adult mammalian brain: "In the adult centers, the nerve paths are something fixed, and immutable: everything may die, nothing may be generated" (3). Besides, probably due to the impossibility to determine with certainty the neural nature of the cells presenting mitotic figures, occasional early reports of neurogenesis in the central nervous system (CNS) were completely ignored (4-5). It was not until more than fifty years later that the pioneering work of Smart et al (6) and Altman (7) demonstrated ongoing neurogenesis, as judged by incor-

Received 1 December 2017, revised 7 December, accepted 8 December 2017.

*Correspondence and reprint request to: Angela Iannitelli, MD, PhD, Department of Biotechnological and Applied

Clinical Sciences, University of L’Aquila, Rome, Italy. E-mail: iannitelliangela@gmail.com 
poration of $3 \mathrm{H}$-thymidine, in some regions of the adult rodent brain. In 1998, overthrowing the dogma of a fixed neuronal complement at birth or soon after, adult neural stem/precursor cells were finally identified as a source of new neurons also in the mammalian CNS including humans (8).

\section{ADOLESCENCE NEUROGENESIS AND SCHIZOPHRENIA}

This had profound implications for adolescent-onset neurodevelopmental disorders such as SCZ. Indeed, since it is now known that neurogenesis, within specific adult brain regions including the dentate gyrus (DG) of the hippocampal formation (HF) and the ventricular zone/subventricular zone/ olfactory bulb (VZ/SVZ/OB) system, continues in postnatal life well into adolescence and beyond, the characteristic age at onset of this disorder - late adolescence or early adulthood, precisely - suggests that $\mathrm{SCZ}$ could arise from a pathological regulation of adult/adolescent neurogenesis (9). In line with this hypothesis, abnormalities of the hippocampus, mainly a subtle but significant volume difference, as well as explicit pathological features in the hippocampus neurogenic niche, are one of the most consistent findings in SCZ research to date (10-22). Moreover, paradigms modelling hippocampal neurogenesis - using fibroblasts-derived induced pluripotent SCs (iPSCs) from patients with SCZ - have found deficits in the generation of DG granule neurons with lowered levels of key embryonic development and/or adult neurogenesis genes, reduced neuronal activity, and reduced levels of spontaneous neurotransmitter release (23). Regarding VZ/SVZ/OB's neurogenic niche, albeit the most common neuroanatomical change in patients with SCZ is enlarged lateral ventricles (13, 24), up to date, no associations have been found between this ventricular enlargement and cytoarchitetural alterations of VZ/SVZ in SCZ (25). In contrast, numerous imaging studies have reported olfactory sulcus depth abnormalities and OB volume reductions in patients diagnosed with SCZ (26, 27 ), also with a number of studies reporting various olfactory deficits (28-30). Of note, these deficits are not explained using medications, cognitive impairments, or smoking status; instead, they support the hypothesis of primary dysfunction in the olfactory system. As for hippocampus, paradigms modelling SCZ - using olfactory mucosal cultures from patients with SCZ - have in fact demonstrated significant diseasespecific alterations in gene expression, protein expression, and cell function, including deregulated neurodevelopmental pathways associated with cell proliferation, adhesion, migration, and cell death (31).
Apart from the prenatal/perinatal period, adolescence has been demonstrated to represent a very sensitive period for brain development. With specific regard to cell proliferation/ survival, studies have shown that adolescents have higher levels of neurogenesis in the hippocampus - an $80 \%$ loss in granule cell production from adolescence to young adulthood (32-34).

\section{ADVERSE LIFE EVENTS AND ADDICTIVE DRUGS IN ADOLESCENCE}

In line with these findings, a decrease in the addiction of new cells during the adolescent period has also been reported in the prefrontal cortex (35). Exposure to adverse life events and/or addictive drugs during adolescence has been linked to deviations in the normal neurodevelopment, in a sort of continuum - starting from the prenatal/perinatal alterations producing a brain particularly at risk of mental diseases such as SCZ (9, 36-39). Delayed maturation and/or damage to specific brain regions, such as the hippocampus and prefrontal cortex, further increase the likehood of ongoing drugs addiction (40). Of note, these same brain regions, in particular hippocampus, are those reported to be significantly affected with regard to neurogenesis when exposed to the aforementioned adolescence SCZ socio-environmental risk factors. What is more with structural, neurochemical, cognitive, and behavioral alterations specific to the SCZ disorder that have been demonstrated in animal models of perturbed neurogenesis (41-43). Chronic social isolation and/or instability, addictive drugs such as opioids, cocaine, cannabinoids, alcohol, nicotine, and even chronic sleep restriction or fragmentation typical of the adolescent period, all have been reported to elicit acute and/or enduring negative effects on adult hippocampal neurogenesis, with the adolescence and/or the young adulthood period which have been proved to be particularly sensitive to their adverse effects $(9,44-52)$. Of note, as for a delayed hippocampus maturation and/or damage, a low hippocampal neurogenic activity has in turn been associated to addiction (53).

Supporting the hypothesis of a combination of different genetic and/or socio-environmentally epigenetic modifications at the base of $\mathrm{SCZ}$, the exposure to the aforementioned adverse life events and/or addictive drugs has been linked to a reduced and/or altered expression/function of the most acknowledged SCZ susceptibility genes [Disrupted in schizophrenia 1 (DISC1); Neuroregulin-1 (NRG-1); MicroRNA-137 (miR137)] and the different intrinsic/extrinsic factors im- 
pacting on adult neurogenesis [Wnt/ $\beta$-catenin; Notch signal; Neural cell adhesion molecule (NCAM); glutamate, GammaAmynobutyric Acid (GABA), Dopamine (DA) and their corresponding receptors; Neurotrophins (NTs)] (9). In a sort of vicious circle, DISC1, NRG-1, NCAM, GABA, DA, and specific NTs alterations (Brain Derived Neurotrophic Factor (BDNF)- Val66Met) have also been indicated as possible contributors to various forms of addiction (9), even with some studies that have demonstrated specific gene environmental stressors (adolescent social isolation/social defeat paradigms, cannabis exposure) interactions affecting brain development and functions during the critical period of adolescence (9).

\section{NEUROPROTECTIVE FACTORS}

In the light of the foregoing, a number of studies have been conducted with the purpose of evaluating the possibility to act on neurogenesis and associated SCZ behavioral/cognitive impairments. Electroconvulsive therapy, atypical antipsychotics, serotoninergic antidepressants as well as agomelatine, lithium, valproate, moderate physical activity and/or environmental enrichment have all been reported to exert a positive effect on neurogenesis, in some cases demonstrating the capacity to protect against the detrimental effect on neurogenesis caused by the aforementioned genetic and/ or epigenetic vulnerabilities (43, 54-61). Recent reviews and various research findings have suggested that glycogen synthase kinase-3beta (GSK-3 $\beta$ ) phosphorylation/inactivation may be central in their mechanisms of action (62-65). Of note, this same molecule represents one of the interacting and/or associated protein of DISC1 gene and even of key signaling controlling adult neurogenesis such as Wnt/ $\beta$ catenin and Reelin (9). Through the inhibition of GSK-3 $\beta$ (or histone deacetylase) via multiple signaling cascades such as the PI3K/Akt and the MAP kinase (MEK)/ERK pathways, all these treatments have been hypothesised to regulate the transcription/expression of different neurotrophic, angiogenic, and neuroprotective proteins (59). Both PI3K/Akt and MEK/ERK pathways have, as a downstream target, the cyclic adenosine monophosphate response element transcription factor (CREB). This latter, when activated through phosphorylation, modulates the expression of neurotrophic and cellprotective proteins, such as brain-derived neurotrophic factor (BDNF), nerve growth factor (NGF), and Bcl-2 (9, 65-67). Noteworthy, BDNF and NGF have been reported to function as both downstream molecules resulting from the inhibition of GSK-3 $\beta$ and upstream signals able to inhibit this molecular

Biomed Rev 28, 2017 pathway $(9,65,68)$.

\section{NGF AS STIMULUS OF ADULT/ADOLESCENT NEUROGENESIS}

With specific regard to NGF, different research findings sug-gest its role in continued neurogenesis and neuroplasticity as well as in the development of various neurological and psy-chiatric disorders characterized by neurocognitive dysfunc-tion including SCZ (69-71). Increased survival of SVZ and/or the hippocampus DG progenitor cells has been observed following the induction of brain NGF synthesis in particular psychosocial stress mouse models $(72,73)$, because of vol-untary moderate physical exercise (74), environmental en-richment $(75,76)$, and/or various pharmacological treatments (76). Intracerebrally injected, NGF also promotes the differentiation of SVZ neuronal precursor cells in aged mice (77) and in animal models of neuroinflammatory brain diseases $(78,79)$, thus indicating how the administration of exogenous NGF can actually mimic the effect of the endogenous form on the immature neuronal cells. Of note, NGF has been proved to exert its biological actions also when applied as eye drops (oNGF) or intranasal (80-83). Early studies in an animal model of diabetes-streptozotocin (STZ) induced cell death demonstrated that oNGF was able to counteract the alteration of mature/pro-NGF expression in the SVZ, affecting the survival and differentiation of SVZ progenitors, further neutralizing the reduction in the number of neuroblast type $\mathrm{A}$ cells and the number and distribution of C-type cells and type B cells (84-86). In a subsequent study, these latter authors reported how oNGF was able to modulate BDNF signaling in the prefrontal cortex of healthy rats and might influence the manifestation of depressive phenotype in diabetic rats (87). In line with these findings, intranasal NGF administration has been reported to rescue neurogenesis and/or neurological im-pairments in animal models of Alzheimer's disease, ischemia as well in patients with severe brain injuries (81-83).

Taken together, these results suggest NGF as one of the strongest stimuli of adult/adolescent neurogenesis, further suggesting the DG of the $\mathrm{HF}$ and the VZ/SVZ/OB system as possible targets for this talented molecule in preventing and/or ameliorating the various behavioral and cognitive SCZ symptoms (88).

\section{ACKNOWLEDGEMENTS}

This study was supported by the Department of Biotechnological and Applied Clinical Sciences, University of L'Aquila. Dr. A. Iannitelli is a recipient of a research grant (SSD MED/25, Rep. n. 43/2017, Prot. n. 685 
19.7.2017), partly supported by “Associazione NGF

Onlus".

\section{REFERENCES}

1. Selemon LD, Zecevic N. Schizophrenia: a tale for two critical periods for prefrontal brain development. Trans Psychiatry 2005; 5: e623. DOI: 10.1038/tp.2015.115.

2. Toro CT, Deakin JF. Adult neurogenesis and schizophrenia: a window on abnormal early brain development? Schizophr Res 2007; 90: 1-14. DOI: 10.1016/j. schres.2006.09.030.

3. Ramon y Cajal S. Degeneration and Regeneration of the Nervous System. Oxford University Press, 1913.

4. Levi G. Sulla cariocinesi delle cellule nervose. Riv Patol Nerv Ment 1898; 3: 97-113.

5. Allen E. The cessation of mitotis in the central nervous system of the albino rat. J Comp Neurol 1912; 19: 547568.

6. Smart I. The subependynal layer of the mouse and its cell production as shown by autograph after [H3] - thymidine injection. J Comp Neurol 1961; 116: 325-327.

7. Altman J. Are new neurons formed in the brains of adult mammals? Science 1962; 135: 1127-1128.

8. Eriksson PS, Perfilieva E, Björk-Eriksson T, Alborn AM, Nordborg C, Peterson DA, et al. Neurogenesis in the adult human hippocampus. Nat Med 1998; 4: 1313-1317. DOI: $10.1038 / 3305$

9. Iannitelli A, Quartini A, Tirassa P, Bersani G. Schizophrenia and neurogenesis: A stem cell approach. Neurosci Biobehav Rev 2017; 80: 414- 442. DOI:10.1016/j.neubiorev.2017.06.010

10. Bogerts B. The temporolimbic system theory of positive schizophrenic symptoms. Schizophrenia Bull 1997; 23: 423-435.

11. Nelson MD, Saykin AJ, Flashman LA, Riordan HJ. Hippocampal volume reduction in schizophrenia as assessed by magnetic resonance imaging: a meta-analytic study. Arch Gen Psychiatry 1998; 55: 433-440.

12. Velakoulis D, Stuart GW, Wood SJ, Smith DJ, Brewer WJ, Desmond P, et al. Selective bilateral hippocampal volume loss in chronic schizophrenia. Biol Psychiatry 2001; 50: 531-539.

13. Steen RG, Mull C, McClure R, Hamer RM, Lieberman JA. Brain volume in first-episode schizophrenia: systematic review and meta-analysis of magnetic resonance imaging studies. Br J Psychiatry 2006; 188: 510-518. DOI: 10.1192/bip.188.6.510

14. Gao XM, Sakai K, Roberts RC, Conley RR, Dean B, Tamminga CA. Ionotropic glutamate receptors and expression of $\mathrm{N}$-methyl-D-aspartate receptor subunits in subregions of human hippocampus: effects of schizophrenia. Am J Psychiatry 2000; 157: 1141-1149. DOI: 10.1176/appi.ajp.157.7.1141

15. Law AJ, Deakin JF. Asymmetrical reductions of hippocampal NMDAR1 glutamate receptor mRNA in the psychoses. Neuroreport 2001; 12: 2971-2974.

16. Kolomeets NS, Orlovskaya DD, Rachmanova VI, Uranova NA. Ultrastructural alterations in hippocampal mossy fiber synapses in schizophrenia: a postmortem morphometric study. Synapse 2005; 57: 47-55. DOI: 10.1002/syn.20153

17. Kolomeets NS, Orlovskaya DD, Uranova NA. Decreased numerical density of CA3 hippocampal mossy fiber synapses in schizophrenia. Synapse 2007; 61: 615-621. DOI: 10.1002/syn.20405

18. Altar CA, Jurata LW, Charles V, Lemire A, Liu P, Bukhman Y, et al. Deficient hippocampal neuron expression of proteasome, ubiquitin, and mitochondrial genes in multiple schizophrenia cohorts. Biol Psychiatry 2005; 58: 85-96. DOI: 10.1016/j.biopsych.2005.03.031

19. Reif A, Fritzen S, Finger M, Strobel A, Lauer M, Schmitt A, et al. Neural stem cell proliferation is decreased in schizophrenia, but not in depression. Mol Psychiatry 2007; 11: 514-522.

20. Walton NM, Zhou Y, Kogan JH, Shin R, Webster M, Gross AK, et al. Detection of an immature dentate gyrus feature in human schizophrenia/bipolar patients. Transl Psychiatry 2011; 2: e135.

21. Hagihara H, Takao K, Walton NM, Matsumoto M, Miyakawa T. Immature dentate gyrus: an endophenotype of neuropsychiatric disorders. Neural Plast 2013; 318596. DOI: 10.1155/2013/318596.

22. Haukvik UK, Westlye LT, Morch-Johnsen L, Jorgensen $\mathrm{KN}$, Lange EH, Dale AM, et al. In vivo hippocampal subfield volumes in schizophrenia and bipolar disorder. Biol Psychiatry 2015; 15: 581-588. DOI: 10.1016/j.biopsych.2014.06.020

23. Yu DX, Di Giorgio FP, Yao J, Marchetto MC, Brennand $\mathrm{K}$, Wright R, et al. Modeling hippocampal neurogenesis using human pluripotent stem cells. Stem Cell Rep 2014; 2: 295-310. DOI: 10.1016/j.stemcr.2014.01.009

24. Shenton ME, Dickey CC, Frumin M, McCarley RW. A 
review of MRI findings in schizophrenia. Schizophr Res 2001; 49: 1-52.

25. Comte I, Kotagiri P, Szele FG. Regional differences in human ependymal and subventricular zone cytoarchitecture are unchanged in neuropsychiatric disease. Dev Neurosci 2012; 34: 299-309. DOI: 10.1159/000338600.

26. Nguyen AD, Pelavin PE, Shenton ME, Chilakamarri P, McCarley RW, Nestor PG, et al. Olfactory sulcal depth and olfactory bulb volume in patients with schizophrenia: an MRI study. Brain Imaging Behav 2011; 5: 252-261. DOI: 10.1007/s11682-011-9129-0

27. Takahashi T, Nakamura Y, Nakamura K, Ikeda E, Furuichi A, Kido M, et al. Altered depth of the olfactory sulcus in first-episode schizophrenia. Progr Neuropsychopharmacol Biol Psychiatry 2013; 40: 167172. DOI: 10.1016/j.pnpbp.2012.10.001

28. Brewer WJ, Pantelis C, Anderson V, Velakoulis D, Singh B, Copolov DL, et al. Stability of olfactory identification deficits in neuroleptic-naive patients with first-episode psychosis. Am J Psychiatry 2001; 158: 107-115. DOI: 10.1176/appi.ajp.158.1.107

29. Rupp CI, Fleischhacker WW, Kemmler G, Kremser C, Bilder RM, Mechtcheriakov S, et al. Olfactory functions and volumetric measures of orbitofrontal and limbic regions in schizophrenia. Schizophr Res 2005, 74: 149161. DOI: 10.1016/j.schres.2004.07.010

30. Good KP, Whitehorn D, Rui Q, Milliken H, Kopala LC. Olfactory identification deficits in first-episode psychosis may predict patients at risk for persistent negative and disorganized or cognitive symptoms. Am J Psychiatry 2006; 163: 932-933. DOI: 10.1176/ ajp.2006.163.5.932.

31. Matigian N, Abrahamsen G, Sutharsan R, Cook AL, Vitale AM, Nouwens A, et al. Disease-specific, neurosphere-derived cells as models for brain disorders. Dis Model Mech 2010; 3: 785-798. DOI: 10.1242/dmm.005447

32. Shors TJ, Townsend DA, Zhao M, Kozorovitskiy Y, Gould E. Neurogenesis may relate to some but not all types of hippocampal-dependent learning. Hippocampus 2002; 12: 578-584.

33. Aimone JB, Wiles J, Gage FH. Potential role for adult neurogenesis in the encoding of time in new memories. Nat Neurosci 2006; 9: 723-727. doi: 10.1038/nn1707

34. He J, Crews FT. Neurogenesis decreases during brain maturation from adolescence to adulthood. Pharmacol Biochem Behav 2007; 86: 327-333. doi: 10.1016/j. pbb.2006.11.003

35. Staffend NA, Mohr MA, DonCarlos LL, Cheryl L, Sisk CL. A decrease in the addition of new cells in the nucleus accumbens and prefrontal cortex between puberty and adulthood in male rats. Dev Neurobiol 2013; 73: 633642. DOI: $10.1002 /$ dneu.22160

36. Malone DT, Hill MN, Rubino T. Adolescent cannabis use and psychosis: epidemiology and neurodevelopmental models. Br J Pharmacol 2010; 160: 511-522. DOI: $10.1111 / \mathrm{j} .1476-5381.2010 .00721 . \mathrm{x}$

37. Bersani G, Iannitelli A. Legalization of cannabis: between political irresponsibility and loss of responsibility of psychiatrists. Riv Psichiatr 2015; 50: 195-198. DOI: 10.1708/2040.22156

38. Holder MK, Blaustein JD. Puberty and adolescence as a time of vulnerability to stressors that alter neurobehavioral processes. Front Neuroendocrinol 2014; 35: 89-110. DOI: 10.1016/j.yfrne.2013.10.004

39. Lubman DI, Cheetham A, Yücel M. Cannabis and adolescent brain development. Pharmacol Ther 2015; 148: 1-16. DOI: 10.1016/j.pharmthera.2014.11.009

40. Brewer WJ, Cstle D, Pantelis C. Olfaction and the Brain 1st ed. Cambridge University Press, 2012.

41. Iwata Y, Suzuki K, Wakuda T, Seki N, Thanseem I, Matsuzaki $\mathrm{H}$, et al. Irradiation in adulthood as a new model of schizophrenia. PLoS One 2008, 28: e2283.

42. Maekawa M, Takashima N, Matsumata M, Ikegami S, Kontani M, Hara Y, et al. Arachidonic acid drives postnatal neurogenesis and elicits a beneficial effect on prepulse inhibition, a biological trait of psychiatric illnesses. PLoS One 2009; 4: e5085.

43. Guo N, Yoshizaki K, Kimura R, Suto F, Yanagawa Y, Osumi N. A sensitive period for GABAergic interneurons in the dentate gyrus in modulating sensorimotor gating. J Neurosci 2013; 10: 6691-6704. DOI: 10.1523/ JNEUROSCI.0032-12.2013

44. Loxton D, Canales JJ. Long-term cognitive, emotional and neurogenic alterations induced by alcohol and methamphetamine exposure in adolescent rats. Prog Neuropsychopharmacol Biol Psychiatry 2017; 74: 1-8. DOI: 10.1016/j.pnpbp.2016.11.003

45. Meerlo P, Mistlberger RE, Jacobs BL, Heller HC, McGinty D. New neurons in the adult brain: the role of sleep and consequences of sleep loss. Sleep Med Rev 2009; 13: 187-194. DOI: 10.1016/j.smrv.2008.07.004

46. McCormick CM, Thomas CM, Sheridan CS, Nixon F, 
Flynn JA, Mathews IZ. Social instability stress in adolescent male rats alters hippocampal neurogenesis and produces deficits in spatial location memory in adulthood. Hippocampus 2012; 22: 1300-1302. DOI: 10.1002/ hipo.20966

47. Cinini SM, Barnabe GF, Galvão-Coelho N, de Medeiros MA, Perez-Mendes P, Sousa MB, et al. Social isolation disrupts hippocampal neurogenesis in young non-human primates. Front Neurosci 2014; 8: 1-9. DOI: 10.3389/ fnins.2014.00045

48. Steel RW, Miller JH, Sim DA, Day DJ. Delta-9tetrahydrocannabinol disrupts hippocampal neuroplasticity and neurogenesis in trained: but not untrained adolescent Sprague-Dawley rats. Brain Res 2014; 22: 12-19. DOI: 10.1016/j.brainres.2013.12.034

49. Ciudad-Roberts A, Duart-Castells L, Camarasa J, Pubill D, Escubedo E. The combination of ethanol with mephedrone increases the signs of neurotoxicity and impairs neurogenesis and learning in adolescent CD-1 mice. Toxicol Appl Pharmacol 2016; 15: 10-20. DOI: 10.1016/ j. taap.2015.12.019

50. Csabai D, Csekö K, Szaiff L, Varga Z, Miseta A, Helyes Z, Czéh, B, et al. Low intensity, long term exposure to tobacco smoke inhibits hippocampal neurogenesis in adult mice. Behav Brain Res 2016; 302: 44-52. DOI: 10.1016/ j. bbr.2016.01.022.

51. Garcia-Cabrerizo R, Garcia-Fuster MJ. Comparative effects of amphetamine-like psychostimulants on rat hippocampal cell genesis at different developmental ages. Neurotoxicology 2016; 56: 29-39. DOI: 10.1016/ j.neu-ro.2016.06.014.

52. Garcia-Fuster MJ, Parsegian A, Watson SJ, Flagel SB. Adolescent cocaine exposure enhances goal-traking behavior and impairs hippocampal cell genesis selectively in adult bred low-resonder rats. Psychopharmacology (Berl.) 2017; 16. DOI: 10.1007/s00213-017-4566-0.

53. Chambers RA. Adult hippocampal neurogenesis in the pathogenesis of addiction and dual diagnosis disorders. Drug Alcohol Depend 2013;130: 1-12. DOI: 10.1016/j. drugalcdep.2012.12.005.

54. Malberg JE, Eisch AJ, Nestler EJ, Duman RS. Chronic antidepressant treatment increases neurogenesis in adult rat hippocampus. J Neurosci 2000; 20: 9104-9110.

55. Stefansson H, Sigurdsson E, Steinthorsdottir V, Bjornsdottir S, Sigmundsson T,Ghosh S. Neuroregulin 1 and susceptibility to schizophrenia. Am J Hum Genet
2002; 71: 877-982. DOI: $10.1086 / 342734$

56. Madsen TM, Newton SS, Eaton ME, Russell DS, Duman RS. Chronic electroconvulsive seizure up-regulates betacatenin expression in rat hippocampus: role in adult neurogenesis. Biol Psychiatry 2003; 54:1006-1014.

57. Chiba S, Hashimoto R, Hattori S, Yohda M, Lipska B, Weinberger DR, et al. Effect of antipsychotic drugs on DISC1 and dysbindin expression in mouse frontal cortex and hippocampus. J Neural Transm (Vienna) 2006; 113: 1337-1346. DOI: 10.1007/s00702-005-0414-1

58. Li C, Niu W, Jiang $\mathrm{CH}$, Hu Y. Effects of enriched environment on gene expression and signal pathways in cortex of hippocampal CA1 specific NMDAR1 knockout mice. Brain Res Bull 2007; 71: 568-577. DOI: 10.1016/j. brainresbull.2006.11.011

59. Chiu CT, Wang Z, Hunsberger JG, Chuang DM. Therapeutic potential of mood stabilizers lithium and valproic acid: beyond bipolar disorder. Pharmacol Rev 2013; 8: 105-142. DOI: 10.1124/pr.111.005512.

60. Bayod S, Mennella I, Sanchez-Roige S, Lalanza JF, Escorihuela RM, Camins A, et al. Wnt pathway regulation by long-term moderate exercise in rat hippocampus. Brain Res 2014; 1543: 38-48. DOI: 10.1016/ j.brain-res.2013.10.048.

61. Yucel A, Yucel N, Ozkanlar S, Polat E, Kara A, Ozcan $\mathrm{H}$, et al. Effect of agomelatine on adult hippocampus apoptosis and neurogenesis using the stress model of rats. Acta Histochem 2016;118: 299-304. DOI: 10.1016/ j.ac-this.2016.02.007.

62. Basar K, Eren-Kocak E, Ozdemir H, Ertugrul A. Effects of acute and chronic electroconvulsive shocks on glycogen synthase kinase $3 \beta$ level and phosphorylation in mice. $J$ ECT 2013; 29: 265-270. DOI:10.1097/ YCT.0b013e318290f7ff.

63. Bunney BG, Li JZ, Walsh DM, Stein R, Vawter MP, Cartagena, $\mathrm{P}$, et al. Circadian dysregulation of clock genes: clues to rapid treatments in major depressive disorder. Mol Psychiatry 2015; 20: 48-55. DOI: 10.1038/mp.2014.138.

64. Kusumi I, Boku S, Takahashi Y. Psychopharmacology of atypical antipsychotic drugs: from the receptor binding profile to neuroprotection and neurogenesis. Psychiatry Clin Neurosci 2015; 69: 243-258. DOI:10.1111/pcn.12242

65. Tirassa P, Quartini A, Iannitelli A. Nerve Growth Factor, Brain-Derived Neurotrophic Factor, and the chronobiology of mood: a new insight into the neurotrophic hypoth- 
esis. Chronophysiol Ther 2016; 5: 51-64. DOI: 10.2147/CPT.S54526

66. Finkbeiner S. CREB couples neurotrophin signals to survival messages. Neuron 2000; 25: 11-14.

67. Lim S, Moon M, Oh H, Kim HG, Kim SY, Oh MS. Ginger improves cognitive function via NGF-induced ERK/CREB activation in the hippocampus of the mouse. J Nutr Biochem 2014; 25; 1058-1065. DOI: 10.1016/j. jnutbio.2014.05.009.

68. Grimes CA, Jope RS. The multifaceted roles of glycogen synthase kinase 3beta in cellular signaling. Prog Neurobiol 2001; 65: 391-426.

69. Curtis MA, Faull RL, Eriksson PS. The effect of neurodegenerative diseases on the sub-ventricular zone. Nat Rev Neurosci 2007; 8: 712-723.

70. Bath KG, Lee FS. Neurotrophic factor control of adult SVZ neurogenesis. Dev Neurobiol 2010; 70: 339-349. DOI: 10.1002/dneu.20781.

71. Gioiosa L, Iannitelli A, Aloe L. Stress, anxiety and schizophrenia and neurotrophic factors: the pioneer studies with nerve growth factor. Riv Psichiatr 2009; 44:88-94. DOI: $10.1708 / 420.4978$

72. Fiore M, Amendola T, Triaca V, Tirassa P, Alleva E, Aloe L. Agonistic encounters in aged male mouse potentiate the expression of endogenous brain NGF and BDNF: possible implication for brain progenitor cells' activation. Eur J Neurosci 2003; 17: 1455-1464.

73. Tzeng WY, Chuang JY, Lin LC, Cherng CG, Lin KY, Chen LH, et al. Companions reverse stressor-induced decreases in neurogenesis and cocaine conditioning possibly by restoring BDNF and NGF levels in dentate gyrus. Psychoneuroendocrinology 2013; 38: 425-437. DOI: 10.1016/j.psyneuen.2012.07.002.

74. Chae CH, Jung SL, An SH, Park BY, Kim TW, Wang SW, et al. Swimming exercise stimulates neuro-genesis in the subventricular zone via increase in synapsin I and nerve growth factor levels. Biol Sport 2014; 31: 309-314. DOI: 10.5604/20831862.1132130.

75. Birch AM, McGarry NB, Kelly AM. Short-term environmental enrichment, in the absence of exercise, improves memory, and increases NGF concentration, early neuronal survival, and synaptogenesis in the dentate gyrus in a time-dependent manner. Hippocampus 2013; 23: 437-450. DOI: 10.1002/hipo.22103.

76. Vilar M, Mira H. Regulation of neurogenesis by neurotrophins during adulthood: expected and unexpect- ed roles. Front Neurosci 2016; 10: 1-9. DOI: 10.3389/fnins.2016.00026.

77. Tirassa P, Triaca V, Amendola T, Fiore M, Aloe L. EGF and NGF injected into the brain of old mice enhance BDNF and ChAT in proliferating subventricular zone. $J$ Neurosci Res 2003; 72: 557-564. DOI: 10.1002/jnr.10614

78. Calza L, Giuliani A, Fernandez M, Pirondi S, D'Intino G, Aloe L, et al. Neural stem cells and cholinergic neurons: regulation by immunolesion and treatment with mitogens retinoic acid, and nerve growth factor. Proc Natl Acad Sci USA 2003; 100: 7325-7330. DOI: 10.1073/ pnas. 1132092100

79. Triaca V, Tirassa P, Aloe L. Presence of nerve growth factor and TrkA expression in the SVZ of EAE rats: evidence for a possible functional significance. Exp Neurol 2005; 191: 53-64. DOI: 10.1016/j.expneurol.2004.08.034

80. Calza A, Florenzano F, Pellegrini D, Tirassa P. Timedependent activation of cfos in limbic brain areas by ocular administration of nerve growth factor in adult rats. J Ocul Pharmacol Th 2011; 27: 209-218. doi: 10.1089/ jop.2010.0139.

81. De Rosa R, Garcia A.A, Braschi C, Capsoni S, Maffei $\mathrm{L}$, Berardi $\mathrm{N}$, et al. Intranasal administration of nerve growth factor (NGF) rescues recognition memory deficits in AD11 anti-NGF transgenic mice. Proc Natl Acad Sci USA 2005; 28: 449-459. DOI: 10.1073/pnas.0500195102

82. Cheng S, Ma M, Ma Y, Wang Z, Xu G, Liu X. Combination therapy with intranasal NGF and electroacupuncture enhanced cell proliferation and survival in rats after stroke. Neurol Res 2009; 31: 753-758. DOI: $10.1179 / 174313209 X 382557$.

83. Chiaretti A, Conti G, Falsini B, Buonsenso D, Crasti M, Manni L, et al. Intranasal Nerve Growth Factor administration improves cerebral functions in a child with severe traumatic brain injury: A case report. Brain Inj 2017; 31:1538-1547. DOI: 10.1080/02699052.2017.1376760.

84. Tirassa P. The nerve growth factor administrated as eye drops activates mature and precursor cells in subventricular zone of adult rats. Arch Ital Biol 2011; 149: 205-213. DOI: 10.4449/aib.v149i1.1359.

85. Tirassa P, Maccarone M, Florenzano F, Cartolano S, De Nicolo S. Vascular and neuronal protection induced by the ocular administration of nerve growth factor in diabetic-induced rat encephalopathy. CNS Neurosci Ther 2013; 19: 307-318. DOI: 10.1111/cns.12085

86. Tirassa P, Maccarone M, Carito V, De Nicolò S, Fiore M. 
Ocular nerve growth factor administration counteracts the impairment of neural precursor cell viability and differentiation in the brain subventricular area of rats with streptozotocin-induced diabetes. Eur J Neurosci 2015; 41: 1207-1218. DOI: 10.1111/ejn.12854

87. Rosso P, De Nicolò S, Carito V, Fiore M, Iannitelli A, Moreno $\mathrm{S}$, et al. Ocular nerve growth factor administration modulates brain-derived neurotrophic factors signaling in pre-frontal cortex of healthy and diabetic rats. CNS Neurosci Ther 2017; 23, 198-208. DOI: 10.1111/ cns. 12661

88. Tirassa P, Rosso P, Iannitelli A. Ocular nerve growth factor (NGF) and NGF eye drop application as paradigms to investigate NGF neuroprotective and reparative actions. Methods in Molecular Biology. In: Neurotrophic Factors, Springer, 2018; In press. 